\title{
Partial-body Cryotherapy (PBC) acutely augments resting metabolism in obese women
}

R. Codella ${ }^{1}$, M.De Nardi ${ }^{2,3}$, S. Delbarba ${ }^{1,2}$, C. Facheris ${ }^{1,2}$, L. Luzi ${ }^{1}$

(1) Department of Biomedical Sciences for Health, Università degli Studi di Milano, Milan, Italy

(2) Krioplanet Ltd, Treviglio, Bergamo, Italy

(3) Dipartimento di Medicina Sperimentale, Università degli Studi di Genova

Cryotherapy has been shown to reduce pro-inflammatory response, relieve pain and enhance muscles' post-exercise recovery. Cryostimulation could be also proposed as an alternative strategy to trigger cold-induced thermogenesis in overweight/obese subjects. In this study, 16 obese (BMI: $\left.32 \pm 4 \mathrm{~kg} / \mathrm{m}^{2}\right)$ women $\left(43.4 \pm 4.8\right.$ years) underwent PBC $\left(-130^{\circ} \mathrm{C} \times 150 \mathrm{sec}\right)$ for 5 days $(1 /$ day, h 07:00 AM). Resting energy metabolism (REE) was assessed by indirect calorimetry pre- and post-PBC on day 1 and day 5 . Subjects were energy-controlled (physical activity and dietary intake). Before $5^{\text {th }}$-day PBC, REE was increased by $5.5 \%$ vs pre- $1^{\text {st }}$-day PBC values $(1755 \pm 265$ vs $1664 \pm 241$ $\mathrm{kcal} / \mathrm{die} ; \mathrm{P}=.0005)$. With the same design, in a larger sample of 80 subjects $(F=61 ; M=19 ; 24.4 \pm 4.8$ years; BMI: $\left.34.4 \pm 11.1 \mathrm{~kg} / \mathrm{m}^{2}\right)$, REE augmented by $1.89 \%(P=.02)$ after PBC of day 1 . In a multivariate analysis, multiple regression output a positive relationship between cryostimulated REE and body weight (Spearman $r=.68 ; P<.0001$, Figure). These preliminary data suggest that cold-induced thermogenesis could be explored as an alternative therapy to combat weight gain and obesity. Longitudinal studies could test chronic effects of cryotherapy, estimating the extent of the metabolic adaptations that could be favorably preserved.

Keywords: cryotherapy, partial-body cryotherapy, resting energy metabolism, weight control 


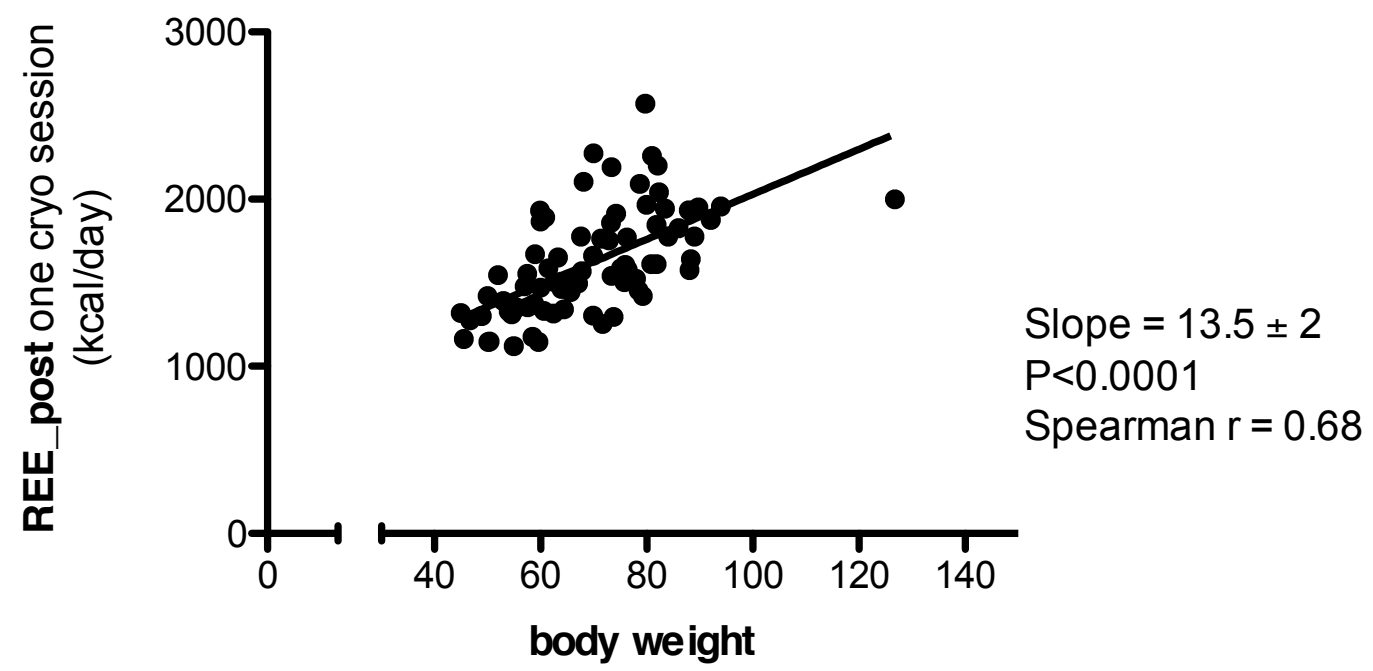

(kg) 